\title{
Olfactory Dysfunction in a Mexican Population Outside of COVID-19 Pandemic: Prevalence and Associated Factors (the OLFAMEX Study)
}

\author{
Irma Yolanda Castillo-López ${ }^{1}$. Luis Humberto Govea-Camacho ${ }^{1}$ - Iván Alejandro Rodríguez-Torres ${ }^{2}$. \\ Denisse Alejandra Recio-Macías ${ }^{1}$ - Isam Alobid $^{3,4}$ • Joaquim Mullol $^{3,4,5}$
}

Accepted: 28 September 2020 / Published online: 8 November 2020

(C) Springer Science+Business Media, LLC, part of Springer Nature 2020

\begin{abstract}
Purpose of Review To study the prevalence of olfactory loss and its associated factors in a Mexican population a cross-sectional analytical study based on a population interviewed about health, epidemiologic aspects, and sense of smell (tested with four scents: rose, banana, perfume, and gas) was conducted to evaluate olfactory detection, memory, and identification. Levels of sense of smell perception were determined when the participants detected, recognized, or identified all (normosmia), 1-3 (hyposmia), or none (anosmia) of the odorants. Associated factors of olfactory dysfunction were identified by multivariate analysis (odds ratio, 95\% CI).

Recent Findings Olfactory dysfunction is a prevalent disorder affecting up to $20 \%$ of the general population. In addition to viral infection, including COVID-19, a number of other causes and factors may also be involved.

Summary 1,956 surveys were conducted and 1,921 were analyzed. Most of the participants $(62.1 \%)$ were women. The general prevalence of olfactory dysfunction, regarding detection, was 7.2\% (7.1\% hyposmia, $0.1 \%$ anosmia). Age-related olfactory deterioration was observed in both sexes from the 5th decade of life (OR 2.74, $p=0.0050$ ). Women showed better olfactory identification (OR $0.73, p=0.0010)$. Obesity (OR 1.97, $p=0.0070$ ), low educational level, bad/very bad self-perceived olfactory function (OR 2.74, $p=0.0050)$, olfactory loss for less than one week (OR 1.35, $p=0.0030)$, exposure to toxics/irritants (OR 1.31, $p=0.0030$ ), active smoking (OR 1.58, $p<0.0010$ ), and type 2 diabetes mellitus (OR 2.68, 95\%CI 1.74-4.10, $p<0.0001$ ) were identified as factors associated with olfactory dysfunction. These results in a Mexican population suggest better olfactory identification (verbalization) in females. Age was a determining factor in the olfactory deterioration process and obesity and diabetes mellitus were also associated with olfactory disorders. Finally, these findings reinforce the differential diagnosis with other potential causes of sense of smell loss, during the COVID-19 outbreak.
\end{abstract}

Keywords Olfactory disorders $\cdot$ Prevalence $\cdot$ Survey $\cdot$ Odorants $\cdot$ Anosmia $\cdot$ COVID-19

This article is part of the Topical Collection on Rhinosinusitis

Irma Yolanda Castillo-López irma.castillol@imss.gob.mx

Joaquim Mullol jmullol@clinic.cat

1 Otolaryngology Department, Specialties Hospital of the National Medical Center of the West, Mexican Institute of Social Security, Independencia Oriente 1000, 44340 Guadalajara, Jalisco, Mexico
2 Area of Chronic Disease and Cancer Detection, Primary Comprehensive Healthcare Administration, IMSS, Mexico City, Mexico

3 Rhinology Unit and Smell Clinic, Otorhinolaryngology Department, Hospital Clinic, Universitat de Barcelona, Barcelona, Spain

4 Clinical and Experimental Respiratory Immunoallergy, IDIBAPS, CIBERES, Barcelona, Catalonia, Spain

5 ENT Department, Hospital Clinic Barcelona-IDIBAPS, Villarroel 170, 08036 Barcelona, Catalonia, Spain 


\section{Introduction}

In the context of the worldwide COVID-19 epidemic, taste and smell disorders have gained public attention due to media diffusion and an increased number of studies $[1 \bullet \bullet, 2]$ highlighting the relevance of those symptoms in the clinical spectrum of COVID-19 infection. In that context, some authors have proposed the suspicion of COVID-19 upon sudden onset of anosmia, even in the absence of other symptoms $[1 \bullet$, 3]. In recent years, the study of olfaction has become relevant because several analyses have suggested that olfactory dysfunction is a marker of health deterioration $[4,5 \cdot, 6]$.

Anosmia and hyposmia are the results of olfactory system dysfunction at different pathway levels. Normosmia is the ability to detect/recognize/identify all odors, hyposmia is the partial olfactory loss, and anosmia is the total olfactory loss. Odor detection is related to the most peripheral part of the olfactory system [7], whereas identification and recognition memory involve cognitive tasks of central structures, such as the orbitofrontal region and other areas of the limbic system. In addition to viral etiology [8, 9], several other causal factors have been described: posttraumatic events [10-12], neurodegenerative diseases [13-15], sinonasal inflammatory diseases (chronic rhinosinusitis, nasal polyps) [16-19], and allergic rhinitis (in adults [20] or children) [21,22].

Several epidemiologic studies have focused on the prevalence (from 1 to $20 \%$ ) of olfactory disorders in the general population, investigating the influence of certain factors on olfactory function [23-28]. Mullol et al. carried out the OLFACAT survey [29] on a Catalan population. Through epidemiologic and health status questionnaires assessing olfaction status, they found a $19.4 \%$ general prevalence of olfactory dysfunction (hyposmia $19.1 \%$ and anosmia $0.3 \%$ ).

The OLFAMEX survey was modeled after the OLFACAT survey, adapting the questionnaire to Mexican health conditions to study the prevalence of normal sense of smell (normosmia) and the loss of sense of smell (hyposmia, anosmia), as well as to identify risk factors associated with olfactory dysfunction, before the COVID-19 outbreak.

\section{Material and Methods}

\section{Study Design}

A cross-sectional analytical study was carried out in Guadalajara (Jalisco, Mexico) from August to October 2017, several years before the COVID-19 outbreak. An epidemiologic and health status survey, together with a smell test (OLFAMEX-4), was conducted on a population from 16 to 100 years of age. Study participants were patients in waiting rooms at a referral hospital center who agreed to be surveyed. Persons with acute upper respiratory infection were excluded.
Age and sex were considered determining factors of olfaction status in the sampling process. The population was stratified by age groups to include females (16-59 years of age), males (16-59 years of age), and older adults of both sexes ( $>60$ years of age), in a representative proportion of the Mexican population.

The study was approved by the Local Research and Ethics Committee. All patients gave their verbal consent to participate in the survey.

\section{Questionnaire 1-Epidemiologic Data and Health Status}

Questionnaire 1 was designed to obtain information on epidemiologic aspects, self-perceived olfactory function, risk exposure history, and specific health conditions. The questionnaire was applied by the research staff and collaborators, with a total of 7 participating physicians. Each investigator carried out an average of 279 surveys over 6 weeks. The epidemiologic data covered the following aspects: sex (male, female), age (years), educational level (none, primary, secondary, university/postgraduate), as well as weight and height, to calculate body mass index (BMI).

Questionnaire 1 contained ten questions (Table 1): two on self-perceived olfactory function: (1) How do you consider your sense of smell? (good, very good, bad, very bad), (2) Have you ever lost your sense of smell? (never, up to 1 week, $>1$ week); two on toxic exposure history: (3) Have you ever been exposed to dust, gases, fumes, vapors, and/or volatile toxic compounds at home and/or in the workplace? (yes, no), (4) Do you smoke? (yes, no); four on health conditions: (5) Have you ever suffered a severe face or head trauma? (yes, no), (6) Have you ever been diagnosed with chronic rhinosinusitis? (yes, no), (7) Have you been diagnosed with type 2 diabetes mellitus (DM2)? (yes, no), (8) Have you or a close relative (parents, brothers, sisters) been diagnosed with Parkinson's disease (PD) or Alzheimer's disease? (yes, no). And finally, two questions on women's health (female participants exclusively): (9) Are you currently pregnant? (yes, no) and (10) Are you currently menstruating? (yes, no).

\section{Questionnaire 2-Smell Test (OLFAMEX-4)}

Once the epidemiologic questionnaire was answered, the bottles containing the odorants were randomly provided, one by one, to each participant, who then was asked to breathe naturally (approximately $5 \mathrm{~s}$ ), after which he/she answered the following questions (Questionnaire 2): (1) Can you smell all the scents? (yes, no), to evaluate odor detection; (2) Have you ever smelled that scent? (yes, no), to evaluate odor recognition memory; and (3) Which name best defines the scent you just smelled? (only one correct option), to evaluate forced-choice odor identification. The term "normosmia" was used when a participant was able to correctly detect, recognize (memory), 
Table 1 OLFAMEX Survey. Epidemiologic characteristics and comparison by sex of the Mexican population studied

\begin{tabular}{|c|c|c|c|c|}
\hline Population characteristic $\dagger$ & Female & Male & Total & $p$-value* \\
\hline Population & $1192(62.1)$ & 729 (37.9) & $1921(100)$ & \\
\hline Age, years (mean $\pm \mathrm{SD})$ & $\underset{\text { o० }}{35.6 \pm 16.7}$ & $\begin{array}{l}34.2 \pm 16.8 \\
\text { ○० }\end{array}$ & 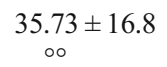 & \\
\hline$<20$ & $301(25.3)$ & $171(23.5)$ & $472(24.6)$ & 0.7060 \\
\hline $20-39$ & $482(40.4)$ & $311(42.7)$ & $793(41.3)$ & \\
\hline $40-59$ & $274(23.0)$ & $170(23.3)$ & $444(23.1)$ & \\
\hline $60 \geq 60$ & $135(11.3)$ & $77(10.6)$ & $212(11.0)$ & \\
\hline Menstruation & $154(12.9)$ & - & $154(8.0)$ & \\
\hline Pregnancy & $84(7.0)$ & - & $84(4.4)$ & \\
\hline Educational level & & & & $<0.0001$ \\
\hline No education & $52(4.4)$ & $10(1.4)$ & $62(3.2)$ & \\
\hline Primary & $337(28.2)$ & $184(25.2)$ & $521(27.1)$ & \\
\hline Secondary & $287(24.1)$ & $219(28.8)$ & $497(25.9)$ & \\
\hline University/college & $516(43.3)$ & $325(44.6)$ & $841(43.8)$ & \\
\hline Body Mass Index & & & & 0.8380 \\
\hline Underweight & $23(1.9)$ & $11(1.5)$ & $34(1.8)$ & \\
\hline Normal & $623(52.2)$ & $390(53.5)$ & $1013(52.7)$ & \\
\hline Overweight & $419(35.2)$ & $256(35.1)$ & $675(35.1)$ & \\
\hline Obesity & $127(10.7)$ & $72(9.9)$ & $199(10.4)$ & \\
\hline Self-perceived olfactory function & & & & 0.1240 \\
\hline Very good & $254(21.3)$ & $168(23.0)$ & $422(22.0)$ & \\
\hline Good & $818(68.6)$ & $467(64.1)$ & $1285(66.9)$ & \\
\hline Bad & $105(8.8)$ & 85 (11.7) & $190(9.9)$ & \\
\hline Very bad & $15(1.3)$ & $9(1.2)$ & $24(1.2)$ & \\
\hline History of olfactory loss & & & & 0.1920 \\
\hline Never & $719(60.3)$ & $469(64.3)$ & $1188(61.8)$ & \\
\hline$\leq 1$ week & $408(34.2)$ & $221(30.3)$ & $629(32.8)$ & \\
\hline$>1$ week & $65(5.5)$ & $39(5.4)$ & $104(5.4)$ & \\
\hline Active smoking & $274(23.0)$ & $255(34.0)$ & $529(27.5)$ & $<0.0001$ \\
\hline Exposure to noxious substances & $566(47.5)$ & $448(61.5)$ & $1014(52.8)$ & $<0.0001$ \\
\hline History of head trauma & $142(11.9)$ & $114(15.6)$ & $256(13.3)$ & 0.0200 \\
\hline History of chronic rhinosinusitis & $72(6.0)$ & $54(7.4)$ & $126(6.6)$ & 0.2400 \\
\hline History of type 2 diabetes mellitus & $138(11.6)$ & $74(10.2)$ & $212(11.0)$ & 0.3330 \\
\hline $\begin{array}{l}\text { History of Parkinson's disease or Alzheimer's } \\
\text { disease }\end{array}$ & $186(15.6)$ & $97(13.3)$ & $283(14.7)$ & 0.1680 \\
\hline
\end{tabular}

or identify all four odorants. When the participant could not correctly detect, recognize (memory), or identify one, two, or three of the four odorants, the term "hyposmia" was used. Finally, the term "anosmia" was used when the participant was unable to detect, recognize (memory), or identify any of the four odorants.

\section{Survey Odorants}

As in the OLFACAT study (28), four common odorants for our population were selected: rose (Bulgarian rose $2 \%$, phenylethyl alcohol 98\%) as a floral scent; banana (isoamyl isobutyrate $50 \%$ in diethyl phthalate) as a food scent; musk (1:1 mixture of galaxolide and exaltolide diethyl phthalate) as a perfume scent; and gas (mixture of $30 \%$ mercaptan and $70 \%$ tetrahydrothiophene) as an industrial scent. A mixture of paraffins and polyethylene glycols with no scent was used as the excipient. Each bottle was numbered from 1 to 4, corresponding to rose $\left(\mathrm{N}^{\circ} 1\right)$, banana $\left(\mathrm{N}^{\circ} 2\right)$, perfume $\left(\mathrm{N}^{\circ} 3\right)$, and gas $\left(\mathrm{N}^{\circ}\right.$ 4). The distractors for those odors were: rose (banana, perfume, gas), banana (rose, perfume, gas), perfume (rose, banana, gas), and gas (rose, banana, perfume). 


\section{Data and Statistical Analysis}

Surveys were manually entered into an Excel database. Detection, recognition memory, and forced-choice identification were analyzed individually. Due to the low prevalence of anosmia for detection and recognition, the sample was merged into two groups: normosmia and olfactory dysfunction (hyposmia plus anosmia). Self-perceived olfactory function was re-grouped into "very good" and "good" sense of smell and compared with "very bad" and "bad" sense of smell. The participants were divided into four age groups: younger than 20 years, 20 to 39 years, 40 to 59 years, and 60 years or older. According to BMI, the participants were grouped into low weight (BMI < 18.5), normal weight (BMI 18.5-24.9), overweight (BMI 25-29.9), and obese (BMI > 29.9), as classified by the World Health Organization [30].

The statistical analysis was performed using the PASW Statistics 18 program. The potential risk factors for the prevalence of olfactory disorders were calculated using age-adjusted logistic regression models (multivariate analysis). Olfactory disorders were the dependent variable. Frequencies and means were calculated for the descriptive statistics, as a hypothesis test by $p$ value (significant when $p<0.0500)$ for the chi-square $\left(\mathrm{Chi}^{2}\right)$ test. The strength of association was determined by the odds ratio ( $95 \%$ confidence interval), calculated to compare the independent variables considered for olfactory loss. The group with the best olfactory ability was the reference. Surveys with inconsistencies or missing data were excluded.

\section{Results}

\section{Characteristics of the Survey Population}

In total, 1956 surveys were carried out, of which 35 were excluded due to inconsistencies or missing data. The final sample size was 1921 surveys (Fig. 1). Table 1 describes the epidemiologic characteristics of the population surveyed.

The overall profile of the OLFAMEX Survey was female, 36 years of age, secondary/university educational level, and normal BMI.

Age and Sex The mean age of the population studied was $35.73 \pm 16.8$ years (range: $16-87) .62 .1 \%(n=1192)$ were female (age: 35.1 years). Young participants (up to 39 years) accounted for $65.9 \%$ (2 out of 3), middle-aged participants (40-59 years) made up $23.1 \%$ ( 1 out of 4 ), and older participants ( $\geq 60$ years) accounted for $11 \%$ ( 1 out of 10 ) of the total (Table 1). Regarding females, $7.4 \%$ were pregnant and $13.1 \%$ were menstruating.
Educational Level $43.8 \%$ reported having a university education, $52 \%$ primary or secondary education, and $3.2 \%$ had no school education. Lack of education was higher in the female group $(4.4 \%$ vs $1.4 \% ; p<0.0010)$

Body Mass Index $52.7 \%$ had normal BMI, $35.1 \%$ had overweight, $0.4 \%$ obesity, and $1.8 \%$ low weight or malnutrition. There were no differences between sexes

Self-Perceived Sense of Smell Sense of smell perception was similar between males and females.

Exposure to Tobacco and Toxic Substances $27.5 \%$ of the participants were active smokers and 1 out of 2 participants $(52.8 \%)$ reported exposure to volatile toxic substances, both conditions being more common in males $(p<0.0001)$

History of Olfactory Loss $61.8 \%$ of participants never noticed olfactory loss, whereas $32.7 \%$ experienced it for $>1$ week, and $5.4 \%$ for $>1$ week, with no differences between sexes

History of Severe Head Trauma 13.3\% reported said condition, which was higher in males ( $15.6 \%$ vs $11.9 \% ; p=0.0200$ )

Health Status $6.6 \%$ of participants had been diagnosed by a physician with chronic rhinosinusitis, $11 \%$ with DM2, and $14.7 \%$ diagnosed with or having a family history of PD or Alzheimer's disease. There were no differences between sexes

\section{Sense of Smell}

Overall Sense of Smell All scents (normosmia) were detected by $92.8 \%$, recognized by $78.6 \%$, and identified by $44.4 \%$ of the participants. Detection, recognition, and identification of $1-3$ scents (hyposmia) was $7.1 \%, 20.9 \%$, and $53.8 \%$, respectively. None of the 4 scents (anosmia) were detected by $0.10 \%$ of the participants, recognized by $0.5 \%$, and identified by $1.8 \%$. Odor detection (rose $97.5 \%$, banana $98.5 \%$, perfume $97.8 \%$, and gas $97.5 \%$ ) was greater than recognition (rose $93.4 \%$, banana $96.0 \%$, perfume $93.4 \%$, and gas $88.0 \%$ ) and forced-choice identification (rose $67.8 \%$, banana $88.9 \%$, perfume $76.3 \%$, and gas $73.0 \%$ ) of the odorants. The most effectively perceived, recognized, and identified scent was banana for the male and female groups.

Olfaction by Sex and Age Only odor identification, not detection or recognition memory, was higher in females $(47.1 \%$ vs $39.9 \%, p=0.0030)$. Detection, recognition, and identification were higher in participants $20-39$ years of age $(95 \%, 83.4 \%$, and $48 \%$ respectively), whereas there was a tendency toward deterioration in participants 40 years of age and older $(p<0.0010)$ (Fig. 2). Participants $>60$ years of age had the highest prevalence of olfactory disorders (hyposmia/anosmia) 


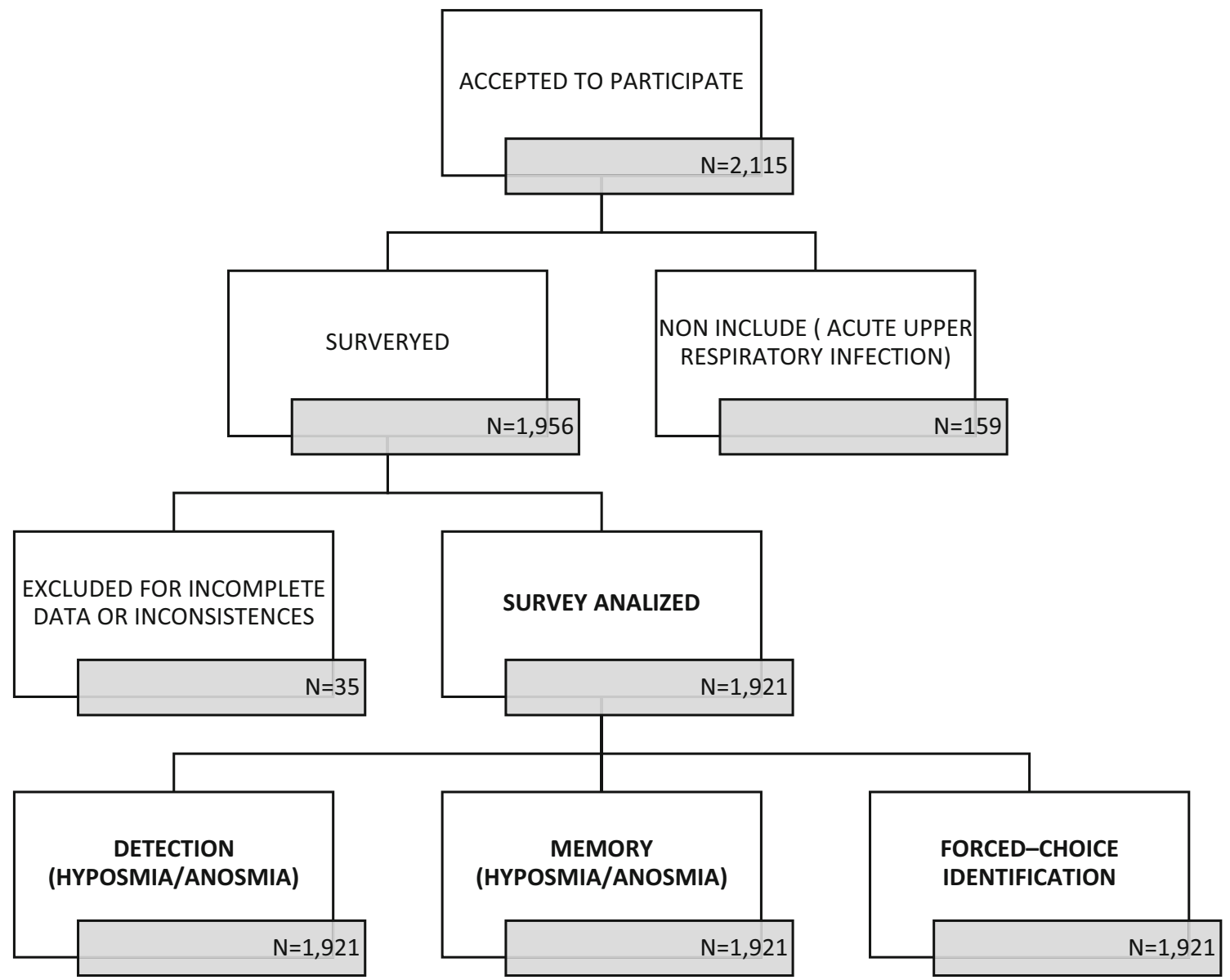

Fig. 1 Flowchart of the OLFAMEX survey participants

for odor detection, recognition, and identification (17.5\%, $31.6 \%$, and $63.7 \%$ respectively) (Fig. 3).

Olfaction and BMI $95.8 \%$ of the participants with normal weight detected all 4 scents (normosmia). That figure dropped to $88.4 \%$ ( $p=0.0420)$ in the obesity group. No differences in odor recognition memory or identification were found.
Olfaction and Educational Level Detection olfactory disorders were more frequent in the participants with educational levels of no school $(16.1 \%)$ and primary school $(10.4 \%)(p<0.0001)$. Recognition memory hyposmia was higher in the group with a primary school education $(22.1 \%)$. The population with no school education showed a higher prevalence of identification anosmia and hyposmia $(4.8 \%, 67.7 \%, p=0.0180)$.
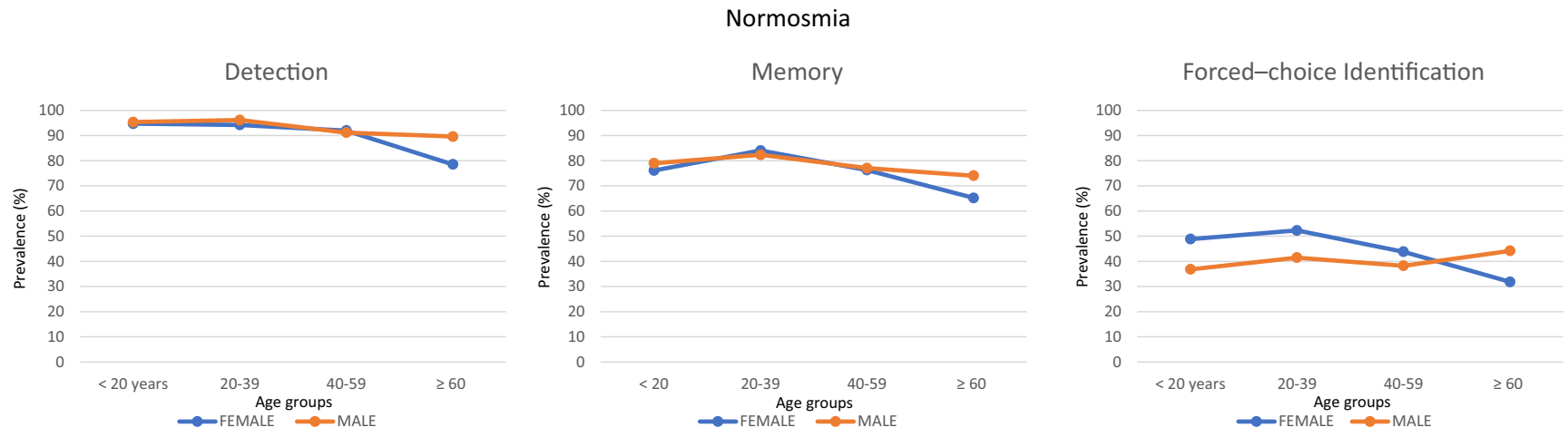

Fig. 2 Lifetime progression of normosmia (perception of all 4 odors). Odor detection, recognition memory, and forced-choice identification reached their highest scores in participants 20 to 39 years of age, with a

tendency to deteriorate in participants 40 years of age and older $(p<0.0010)$ 
Olfactory dysfunction
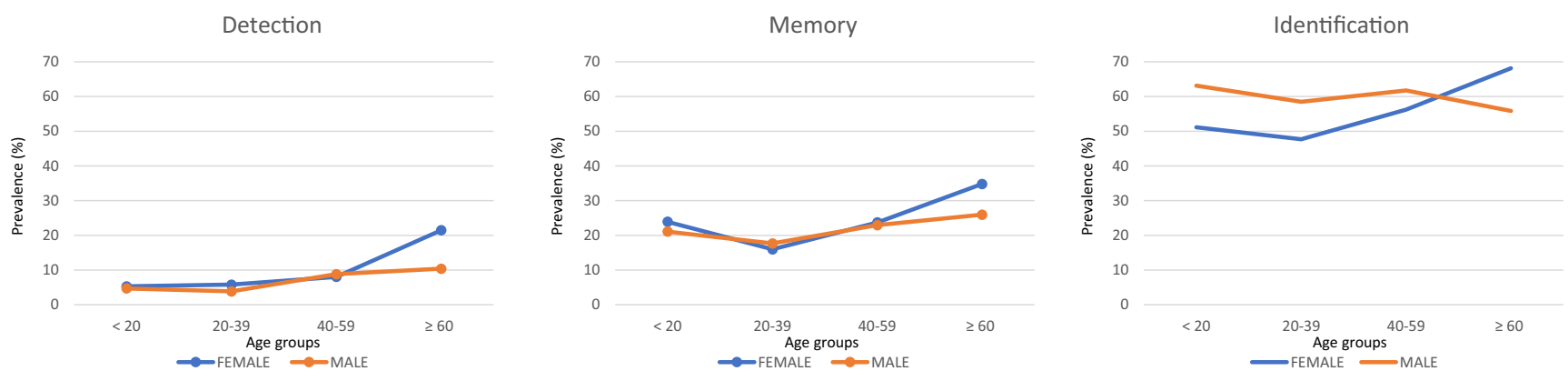

Fig. 3 Lifetime progression of olfactory dysfunction (olfactory loss in $\geq 1$ more odors). The highest prevalence of olfactory dysfunction in odor detection, recognition memory, and forced-choice identification was

observed in participants $>60$ years of age. Women showed better identification skills than men $(p=0.0333)$, except in older adults

Self-Perceived Sense of Smell Regardless of sex, most participants $(88.9 \%)$ reported having a good or very good sense of smell, whereas only $11.1 \%$ stated having a bad or very bad sense of smell. Most participants (79.5\%) with detection hyposmia reported a good or very good sense of smell, whereas only a few $(13.2 \%)$ of the subjects with identification hyposmia reported a bad or very bad sense of smell. Finally, only 1 of every 2 participants $(50.2 \%)$ that reported having a good sense of smell, correctly identified the four odorants $(p<0.0001)$.

Olfaction and History of Olfactory Loss One-third (35.5\%) of the participants with identification hyposmia reported having a history of olfactory loss for $<1$ week. Regarding the history of olfactory loss for more than a week, the answer was significantly much lower in participants with normosmia than those with anosmia $(11.4 \%)(p=0.0100)$.

\section{Factors Associated with Olfactory Dysfunction (Hyposmia + Anosmia)}

Odor Detection In our Mexican population, sex was not associated with differences in olfactory detection. In contrast, a lack of education (OR 2.74) was associated with a poor sense of smell, and low weight (OR 2.6), obesity (OR 1.97), DM2 (OR 2.69), and bad or very bad self-perceived sense of smell (OR 2.30) were associated with olfactory dysfunction. Additionally, age over 70 years increased the risk for an olfactory dysfunction by almost 4 times (OR 3.98), and to a lesser extent, in the 40 to 59-year age group (OR 1.71) (Table 2).

Odor Recognition Memory The participants 20 and 40 years of age showed the best skills for olfactory recognition, whereas recognition hyposmia/anosmia was associated with those that were younger or older ( $<20$ years: OR $1.49 ; 40-59$ years: OR 1.53 ; $\geq 60$ years: OR 2.31). Obesity (OR 1.45), bad or very bad self-perceived sense of smell (OR 1.76), and history of olfactory loss $<1$ week (OR 1.36) were also associated with olfactory loss. On the other hand, pregnancy seemed to be associated with better olfactory recognition (OR 0.36). (Table 2).

Odor Identification Females identified odorants better than males (OR 0.73). As in detection and recognition memory, older age (OR 1.51), low educational level (OR 2.08), and poor self-perceived olfactory function (OR 1.84) were associated with odor identification hyposmia.

A personal history of olfactory loss for $<1$ week (OR 1.35), smoking (OR 1.58), exposure to toxic substances (OR 1.32), and diabetes mellitus (OR 1.78) were also associated with worse odor identification, whereas pregnancy was associated with better odor identification (OR 0.25).

Identification anosmia was found in $1.8 \%$ of the participants and older age (OR 5.94), lack of education (OR 4.45), diabetes mellitus (OR 4.06), and poor self-perceived olfactory function (OR 7.16) were also associated with anosmia (Table 3).

\section{Discussion}

Highlighting the most important results of our study on the general prevalence of olfactory disorders, first, regarding odor detection, we found hyposmia $(7.1 \%)$ and anosmia $(0.1 \%)$ in $7.2 \%$ of the Mexican population analyzed. Second, there was a tendency toward age-related olfactory deterioration in both sexes, finding the best olfactory abilities in the 20 to 39 year age group, with progressive deterioration from the 5 th decade of life, for odor detection, recognition memory, and forcedchoice identification. Third, both sexes showed very similar olfactory abilities for odor detection and recognition, but odor identification was significantly better in females in all age groups, except for the 7th decade of life. Fourth, pregnancy, but not menstruation, was associated with better odor recognition and identification. Fifth, obesity, low school education, 
Table 2 Relative risk (OR) for odor detection and recognition/memory olfactory dysfunction (hyposmia + anosmia) using a multivariate logistic analysis of demographic characterisitics and health problems

\begin{tabular}{|c|c|c|c|c|c|c|c|c|c|c|}
\hline \multirow[t]{3}{*}{ Covariate } & \multicolumn{5}{|c|}{ Olfactory dysfunction (detection) } & \multicolumn{5}{|c|}{ Olfactory dysfunction (recofnition/memory) } \\
\hline & \multicolumn{5}{|c|}{$\begin{array}{l}1921 \text { subjects [136 with hyposmia }(7.1,2 \text { with anosmia } \\
(0.1 \%) \%)\end{array}$} & \multicolumn{5}{|c|}{$\begin{array}{l}1921 \text { subjects [ } 401 \text { with hyposmia }(20.9 \%), 10 \text { with } \\
\text { anosmia }(0.5 \%) \text { ] }\end{array}$} \\
\hline & No & Yes & OR & $(95 \%$ IC) & $p$ value & No & Yes & OR & (95\% IC) & $p$ value \\
\hline Female & $1097(92)$ & $95(8)$ & 1.38 & $(0.95-2.00)$ & 0.0880 & $931(78.1)$ & $261(21.9)$ & 1.08 & $(0.86-1.36)$ & 0.494 \\
\hline \multicolumn{11}{|l|}{ Age (years) } \\
\hline$<20$ & $448(94.9)$ & $24(5.1)$ & 1.01 & $(0.60-1.69)$ & 0.9750 & $364(77.1)$ & $180(22.9)$ & 1.49 & $(1.12-1.97)$ & 0.006 \\
\hline $20-39^{*}$ & $753(95)$ & $40(5)$ & 1 & - & _- & $661(83.4)$ & $132(16.6)$ & 1 & _ & _ \\
\hline $40-59$ & $407(91.7)$ & $37(8.3)$ & 1.71 & $(1.07-2.71)$ & 0.0220 & $340(76.6)$ & $104(23.4)$ & 1.53 & $(1.14-2.04)$ & 0.0040 \\
\hline 60 or more & $175(82.5)$ & $37(17.5)$ & 3.98 & $(2.47-6.40)$ & $<0.0010$ & $145(68.4)$ & $37(31.6)$ & 2.31 & $(1.63-3.26)$ & $<0.0010$ \\
\hline Menstruation & $144(93.5)$ & $10(6.5)$ & 0.77 & $(.39-1.53)$ & 0.4690 & $123(79.9)$ & $31(20.1)$ & 0.88 & $(.58-1.34)$ & 0.5700 \\
\hline Pregnancy & $81(96.4)$ & $3(3.6)$ & 0.4 & $(.12-1.32)$ & 0.1230 & $76(90.5)$ & $8(9.5)$ & 0.35 & $(.16-.71)$ & 0.0040 \\
\hline \multicolumn{11}{|l|}{ Education level } \\
\hline No education & $52(83.9)$ & $10(16.1)$ & 2.74 & $(1.32-5.70)$ & 0.0050 & $52(83.9)$ & $10(16.1)$ & 0.69 & $(.34-1.39)$ & 0.3060 \\
\hline Primary & $466(89.4)$ & $55(10.6)$ & 1.68 & $(1.14-2.49)$ & 0.0080 & $402(77.2)$ & $119(22.8)$ & 1.07 & $(0.82-1.39)$ & 0.6040 \\
\hline Secondary & $479(96.4)$ & $18(3.6)$ & 0.53 & $(.31-.92)$ & 0.0230 & 397 (79.9) & $100(20.1)$ & 0.91 & $(.69-1.11)$ & \\
\hline University/college & $786(93.5)$ & $55(6.5)$ & 1 & - & - & $659(78.4)$ & $182(21.6)$ & 1 & _ & - \\
\hline \multicolumn{11}{|l|}{ Body mass index } \\
\hline Under weight & $29(85.3)$ & $5(14.7)$ & 2.6 & $(.97-6.94)$ & 0.0480 & $24(70.6)$ & $10(29.4)$ & 1.65 & $(.77-3.51)$ & 0.1870 \\
\hline Normal & $950(93.8)$ & $63(6.2)$ & 1 & _ & _- & 809 (79.9) & $204(20.1)$ & 1 & _ & - \\
\hline Over weight & $628(93)$ & $47(7)$ & 1.12 & $(.76-1.66)$ & 0.5440 & $532(78.8)$ & $143(21.2)$ & 1.06 & $(.83-1.35)$ & 0.6020 \\
\hline Obesity & $176(88.4)$ & $23(11.6)$ & 1.97 & $(1.19-3.26)$ & 0.0070 & $145(72.9)$ & $54(27.1)$ & 1.44 & (1.04-2.09) & 0.0270 \\
\hline \multicolumn{11}{|l|}{ Olfactory self-perception } \\
\hline Very good/good & $1598(93.6)$ & $109(6.4)$ & 1 & _ & _ & $1362(79.8)$ & $345(20.2)$ & 1 & _ & _ \\
\hline Very bad/bad & $185(86.4)$ & $29(13.6)$ & 2.29 & $(1.48-3.55)$ & $<0.0001$ & $148(69.2)$ & $66(30.8)$ & 1.76 & $(1.28-2.40)$ & $>0.0010$ \\
\hline \multicolumn{11}{|l|}{ History of olfactory loss } \\
\hline Never & $1104(92.9)$ & $84(7.1)$ & 1 & _ & _ & $954(80.3)$ & $234(19.7)$ & 1 & & \\
\hline$\leq 1$ week & $584(92.8)$ & $45(7.2)$ & 1.01 & $(.69-1.47)$ & 0.9470 & $472(75)$ & $157(25)$ & 1.35 & $(1.07-1.70)$ & 0.0090 \\
\hline$>1$ week & $95(91.3)$ & $9(8.7)$ & 1.24 & $(.60-2.55)$ & 0.5490 & $84(80.8)$ & $20(19.2)$ & 0.97 & $(0.58-1.61)$ & 0.9090 \\
\hline Active smoking & 485 (91.7) & $44(8.3)$ & 1.25 & $(0.86-1.81)$ & 0.2350 & $421(79.6)$ & $108(20.4)$ & 0.92 & $(.72-1.18)$ & 0.5190 \\
\hline Exposure to noxious substances & $947(93.4)$ & $67(6.6)$ & 0.83 & $(.58-1.17)$ & 0.3010 & $797(78.6)$ & $217(21.4)$ & 1 & $(.80-1.24)$ & 0.9550 \\
\hline History of cranial trauma & $231(90.2)$ & $25(9.8)$ & 1.48 & $(.94-2.34)$ & 0.0860 & $197(77)$ & $59(23)$ & 1.11 & $(.81-1.52)$ & 0.4890 \\
\hline Chronic rhinosinusitis & $114(90.5)$ & $12(9.5)$ & 1.39 & $(.74-2.59)$ & 0.2930 & $98(77.8)$ & $28(22.2)$ & 1.05 & $(.68-1.62)$ & 0.8150 \\
\hline Diabetes mellitus II & $180(84.9)$ & $32(15.1)$ & 2.68 & $(1.75-4.10)$ & $<0.0001$ & $162(76.4)$ & $50(23.6)$ & 1.15 & $(.82-1.61)$ & 0.4100 \\
\hline Parkinson or Alzheimer & $266(94)$ & $17(6)$ & 0.8 & $(.47-1.35)$ & 0.4060 & $224(79.2)$ & $59(20.8)$ & 0.96 & $(.70-1.31)$ & 0.9520 \\
\hline
\end{tabular}

${ }^{*}$ Reference value for OR

bad/very bad self-perceived olfactory function, history of olfactory loss for less than 1 week, exposure to toxins, active smoking, and DM2 were also associated with olfactory disorders. Sixth and last, neither head trauma nor the history of chronic rhinosinusitis was associated with the development of olfactory loss.

By 2015, Mexico had a population of 87 million inhabitants, 15 years of age or older [31]. According to the prevalence of olfactory loss found (7.2\%) in our study, we estimate that around 6 million Mexicans have some degree of olfactory dysfunction, of which they are unaware (79.5\% of participants with detection hyposmia perceived their sense of smell as good or very good). We based our prevalence study on the Catalan OLFACAT Survey [29] regarding odor detection, recognition memory, and forced-choice identification. Although the prevalence of detection hyposmia in our population was lower than that reported in the OLFACAT survey (7.2\% vs $19.4 \%)$, odor identification was similar $(55.6 \%$ vs $48.8 \%$ ). Those differences can be explained by the demographic characteristics in the two populations, with a tendency 
Table 3 Relative risk (OR) for forced-choice identification hyposmia and anosmia using a multivariate logistic analysis of demographic characteristic and health problems

\begin{tabular}{|c|c|c|c|c|c|c|c|c|c|c|}
\hline \multirow[t]{3}{*}{ Covariate } & \multicolumn{5}{|c|}{ Hyposmia (forced-choice identification) } & \multicolumn{5}{|c|}{ Anosmia (forced-choice identification) } \\
\hline & \multicolumn{5}{|c|}{$\begin{array}{l}1921 \text { subjects (excluding } 35 \text { with anosmia), } 1033 \text { with } \\
\text { hyposmia }(53.7 \%)\end{array}$} & \multicolumn{5}{|c|}{$\begin{array}{l}1921 \text { subjects (excluding } 1033 \text { with hyposmia), } 35 \text { with } \\
\text { anosmia }(1.8 \%)\end{array}$} \\
\hline & No & Yes & OR & (95\% IC) & $p$ value & No & Yes & OR & $(95 \%$ IC) & $p$ value \\
\hline Female & $562(47.1)$ & $605(50.8)$ & 0.73 & $(.60-.88)$ & 0.0010 & $562(95.7)$ & $25(4.3)$ & 1.29 & $(.61-2.73)$ & 0.4970 \\
\hline \multicolumn{11}{|l|}{ Age (years) } \\
\hline$<20$ & $210(45)$ & $257(55)$ & 1.16 & $(.92-1.46)$ & 0.2060 & $210(97.7)$ & $5(2.3)$ & 0.9 & $(.306-2.689)$ & 0.8600 \\
\hline $20-39^{*}$ & $381(48.7)$ & $402(51.3)$ & 1 & - & - & $381(97.4)$ & $10(2.6)$ & 1 & - & - \\
\hline $40-59$ & $185(42.4)$ & $251(57.6)$ & 1.28 & $(1.01-1.62)$ & 0.0370 & $185(95.9)$ & $8(4.1)$ & 1.64 & $(064-4.24)$ & 0.2960 \\
\hline 60 or more & $77(38.5)$ & $123(61.5)$ & 1.51 & $(1.10-2.08)$ & 0.0100 & $77(86.5)$ & $12(13.5)$ & 5.93 & $(2.47-14.23)$ & $<0.0010$ \\
\hline Menstruation & $70(46.4)$ & $81(53.6)$ & 1.08 & $(.77-1.53)$ & 0.6350 & $70(95.9)$ & $3(4.1)$ & 0.95 & $(.28-3.28)$ & 0.9460 \\
\hline Pregnancy & $64(77.1)$ & 19 (22.9) & 0.25 & $(.14-.42)$ & $<0.0010$ & $64(98.5)$ & $1(1.5)$ & 0.32 & $(.04-2.43)$ & 0.2490 \\
\hline \multicolumn{11}{|l|}{ Education level } \\
\hline No education & $17(27.4)$ & $42(67.7)$ & 2.08 & $(1.16-3.72)$ & 0.0110 & $17(27.4)$ & $3(4.8)$ & 4.44 & $(1.17-16.83)$ & 0.0170 \\
\hline Primary & $242(46.4)$ & $266(51.1)$ & 0.92 & $(.74-1.15)$ & 0.5050 & $242(46.4)$ & $13(2.5)$ & 1.35 & $(.63-2.89)$ & 0.4330 \\
\hline Secondary & $216(43.5)$ & $277(55.7)$ & 1.08 & $(.86-1.35)$ & 0.4910 & $216(43.5)$ & $4(0.8)$ & 0.46 & $(.15-1.42)$ & 0.1710 \\
\hline University/college ${ }^{*}$ & $378(44.9)$ & $448(53.3)$ & 1 & - & - & $378(44.9)$ & $15(1.8)$ & 1 & - & - \\
\hline \multicolumn{11}{|l|}{ Body mass index } \\
\hline Under weight & $15(45.5)$ & $18(54.5)$ & 1.06 & $(.53-2.13)$ & 0.8620 & 15 (93.9) & $1(6.2)$ & 2.08 & $(.25-16.82)$ & 0.4810 \\
\hline Normal & $469(47)$ & $529(53)$ & 1 & _- & _- & 469 (96.9) & $15(3.1)$ & 1 & _ & - \\
\hline Over weight & $290(43.9)$ & $371(56.1)$ & 1.13 & $(.93-1.38)$ & 0.2120 & $290(95.4)$ & $14(4.6)$ & 1.5 & $(.71-3.17)$ & 0.2740 \\
\hline Obesity & $79(40.7)$ & $115(59.3)$ & 1.12 & $(.94-1.76)$ & 0.1090 & $79(94)$ & $5(6)$ & 1.97 & $(.70-5.59)$ & 0.1900 \\
\hline \multicolumn{11}{|l|}{ Olfactory self-perception } \\
\hline Very good/good & $788(46.8)$ & $897(53.2)$ & 1 & - & - & $788(97.3)$ & $22(2.7)$ & 1 & - & - \\
\hline Very bad/bad & $65(32.3)$ & $136(67.7)$ & 1.83 & $(1.34-2.50)$ & $<0.0001$ & $65(83.3)$ & $13(16.7)$ & 7.16 & $(3.44-14.87)$ & $<0.0010$ \\
\hline \multicolumn{11}{|l|}{ History of olfactory loss } \\
\hline Never & $562(48.2)$ & $605(51.8)$ & 1 & - & - & $562(96.4)$ & $21(3.6)$ & 1 & - & - \\
\hline$\leq 1$ week & $252(40.7)$ & $367(59.3)$ & 1.35 & $(1.11-1.64)$ & 0.0030 & $252(96.2)$ & $10(3.8)$ & 1.06 & $(.49-2.28)$ & 0.8780 \\
\hline$>1$ week & $39(39)$ & $61(61)$ & 1.45 & $(.95-2.20)$ & 0.0780 & $39(90.7)$ & $4(9.3)$ & 2.74 & $(.89-8.39)$ & 0.0650 \\
\hline Active smoking & $192(37.1)$ & $325(62.9)$ & 1.58 & $(1.28-1.94)$ & $<0.0010$ & $192(36.3)$ & $12(2.3)$ & 1.79 & $(.84-3.67)$ & 0.1050 \\
\hline Exposure to noxious substances & $418(42)$ & $577(58)$ & 1.31 & $(1.09-1.58)$ & 0.003 & $418(94.1)$ & $19(5.9)$ & 1.23 & $(.62-2.43)$ & 0.5400 \\
\hline History of cranial trauma. & $113(44.8)$ & $139(55.2)$ & 1.01 & $(.78-1.32)$ & 0.8950 & $113(96.6)$ & $4(3.4)$ & 0.84 & $(.29-2.43)$ & 0.7550 \\
\hline Chronic rhinosinusitis & $46(37.4)$ & $77(62.6)$ & 1.41 & $(.96-2.06)$ & 0.0710 & $46(93.9)$ & $3(6.1)$ & 1.64 & $(.48-5.57)$ & 0.4200 \\
\hline Diabetes Mellitus II & $67(33)$ & $136(67)$ & 1.77 & $(1.30-2.42)$ & $<0.0010$ & $67(88.2)$ & $9(11.8)$ & 4.06 & $(1.82-9.02)$ & $<0.0010$ \\
\hline Parkinson or Alzheimer & $112(40)$ & $168(60)$ & 1.28 & $(.99-1.66)$ & 0.0570 & $112(97.4)$ & $3(2.6)$ & 0.62 & $(.18-2.05)$ & 0.4310 \\
\hline
\end{tabular}

${ }^{*}$ Reference value for OR

toward a younger population with a lower educational level in the OLFAMEX survey. Detection hyposmia is expected to be lower in a younger population, but its relation to recognition and identification, which depend on cognitive and semantic capability, is less clear. [32] Several studies have focused on olfactory disorders in the general population, reporting a prevalence of 1 to $20 \%$. That wide range is due to the diversity of methods used for assessing olfaction [23-29]. Researchers are currently encouraging the use of universal language and methodological quality so there can be the consistency of results in this field [33].
In recent decades, the world population has shown a tendency toward aging. By the year 2030, there will be $55 \%$ more adults reaching the 7th decade of life in Mexico [31]. A significant number of that older population will experience agerelated sensory loss and a worsening in general health, wellbeing, self-sufficiency, and quality of life. In the OLFAMEX study, a strong decrease in olfactory identification was demonstrated in the 6th and 7th decades of life, with more than half of the participants $>65$ years of age having significant olfactory disorders [23-25, 27, 29, 34]. Thus, we observed a 
higher prevalence of olfactory dysfunction from the 6th decade of life.

In our Mexican study population, aging was associated with detection, recognition memory, and identification of olfactory dysfunction. Different agents, acting alone or together, can potentially explain that deterioration. An increase in the number of patches of respiratory epithelium, which represents a loss of primary olfactory receptor neurons, has been found in the olfactory zone in the older adult population [35], as well as a decrease in the expression of olfactory receptors in olfactory mucosa, predominating in men [36]. Similarly, exposure to harmful agents, the risk of head trauma from falls, the prevalence of diseases, such as diabetes mellitus and neurodegenerative diseases, increase with aging. The National Social Life and Aging Project (NSHAP) study [4], conducted in the US from 2005 to 2011 on an older adult population, found that 5year mortality was associated with hyposmia (OR 1.54) and highly associated with anosmia (OR 3.24). They concluded that olfactory dysfunction is one of the strongest 5-year predictors (together with heart failure, diabetes, and stroke) of mortality and can serve as a marker of accumulated toxic environmental exposures.

A majority of studies have found that females have better olfactory identification than males, both in free and forcedchoice responses [27, 29, 37, 38]. In the OLFACAT survey, Mullol et al. reported that women had higher detection, recognition memory, and forced-choice identification skills than men [29]. However, the findings on olfactory sensitivity are inconclusive. In a study involving 154 adults, Gouveri et al. [39] found no differences in detection skills and olfactory discrimination between males and females. In our study, females showed a higher capacity for forced-choice identification (OR 0.73) but, as in Gouveri's study, we found no differences for detection and recognition. It is well-known that olfactory identification involves a semantic memory task that requires individual knowledge of a specific odor [40]. Larsson et al. [32] also found that olfactory information verbalization was higher in females, suggesting a better olfactory identification capacity, as well.

Traditionally, pregnancy has been associated with a sharper sense of smell and most pregnant females report an increase in odor detection. However, Ochsenbein-Kolble et al. [41] objectively evaluated olfactory function, finding no increase in olfactory sensitivity during pregnancy. In fact, they found a decrease in olfactory sensitivity detected in late pregnancy, which remained even after delivery. Contrastingly, we observed a lower prevalence of olfactory disorders for recognition memory and a greater ability to identify odorants in the Mexican female population. That phenomenon could be explained by the evidence that pregnant females can better identify certain odors than controls [42-45] but further comparative studies are needed to establish a clear association between pregnancy and olfactory identification.
Mexico is the second country worldwide with the highest prevalence of obesity, at $30 \%$ in the adult population [46]. The impact of obesity on cardiovascular (cerebral vascular disease, blood hypertension) and metabolic (diabetes mellitus) systems have been widely studied. The olfactory and endocrine systems appear to be connected, with important roles played by insulin, ghrelin, and leptin. Similarly, a high-fat diet can affect the general neuro-architecture of the olfactory system by reducing the number of olfactory receptor neurons and their axonal projection [47]. The lower the olfactory function, the higher the emotional consumption of food and the consequent increase in BMI [48]. In our study, obesity was associated with odor detection loss by $97 \%$ and recognition memory by $44 \%$. That situation is a great challenge for the comprehensive management of obesity and partially explains the difficulty of adhering to a healthy diet, since obesity may be a significant cause-effect in olfactory disorders. Said event is even more relevant in older adults, in whom olfactory impairment plays a role in poorer diet quality [49••].

Several studies have shown an independent association between olfactory loss and DM2. Patients with the microvascular disease caused by DM2 exhibit a particularly severe deterioration in olfaction $[38,50]$. Similarly, an association between low olfactory scores and DM2 complications has been found [51]. Gascon et al. [52] described a decrease in the percentage of correct responses indirectly related to increased albuminuria and low glomerular filtration rate. Those findings suggest that olfactory tests may be used for the early recognition of DM2 complications. In our study, DM2 was associated with the detection and identification of hyposmia, and even with anosmia.

The impact of formal education on neurodegenerative diseases and behavioral functions has been widely studied. The theory of cognitive reserve posits that highly educated individuals suffering from brain diseases are more likely to use strategies to recruit brain structures other than those normally used in cognitive tasks [32]. The identification of an odorant requires semantic memory, which is a cognitive ability that is increased by formal education [53]. Some studies [29, 32] have reported that a high educational level improves the capacity of odor recognition memory and identification. Similarly, in the OLFAMEX survey, we found higher skills for odor detection, recognition memory, and identification in the middle/high educational level groups. The participants that could not read or write had a 2 to 3-times higher association with recognition and identification of olfactory disorders.

Exposure to toxins, as potential olfactory disorder-inducing agents, is the cause in 1-5\% of those conditions and its impact is clearly underestimated, especially in individuals with chronic long-term exposure [54]. In the OLFAMEX survey, exposure to toxic/harmful substances was associated with identification hyposmia. The impact of smoking on the respiratory tract and its inflammatory, mutagenic, and carcinogenic 
effects are well known. Despite contradictory study results, structural or functional changes have been found in the olfactory neuroepithelium, suggesting that smoking may impact odor detection and recognition memory [55]. Bramerson et al. [27] found no differences between the threshold and discriminative capacity in smokers and non-smokers but Mullol et al. [29] found that smoking was associated with better odor recognition memory. In our study, as in previous studies, active smoking and olfactory dysfunction were associated.

Neurodegenerative diseases are relevant to olfactory disorders. Early olfactory deficits have been observed in patients with Alzheimer's disease. The first to be altered [35] is odor identification because certain medial temporal lobe structures involved are affected in the early stages of Alzheimer's disease [56]. Similarly, olfactory deficits can be found early on in patients with PD. Olfactory dysfunction is the second most common characteristic after rigidity and akinesia and could even be the most frequent early alteration [14]. A study involving 48 relatives of persons with PD (25 individuals with hyposmia and 23 with normosmia) found that $8 \%$ of individuals with hyposmia developed PD compared with $0 \%$ of individuals with normosmia, indicating that olfactory disorders precede the classic clinical motor signs of the disease [57]. Our results showed that participants with a personal or family history of those diseases had difficulty correctly identifying odorants, and $28 \%$ had hyposmia. Taking into account the significant number of dopaminergic neurons lost at the time of clinical diagnosis of $\mathrm{PD}$, the detection of patients in the prodromal period of clinical parkinsonism is very important for the development of treatment strategies that reduce or prevent motor PD [14, 58, 59].

Although chronic rhinosinusitis [60] and head trauma have been associated as frequent causes of olfactory deficit [11,61], we found no associations with an increased prevalence of hyposmia/anosmia. Nevertheless, a personal history of olfactory loss for $<1$ week appears to be associated with olfactory loss, with respect to both memory and identification. Postviral etiology is frequently associated with olfactory loss in the course of acute manifestations, such as nasal blockage and rhinorrhea $[8,9]$. In the COVID-19 epidemic, evidence has emerged that reveals the appearance of olfactory alterations as one of the most common signs of that viral infection $[1 \bullet, 2$, $60,62]$. Some authors suggest that anosmia could be the only clinical presentation, without any other significant symptoms [3], or even an early sign of COVID-19 infection [62]. In the context of post-viral olfactory loss, the mechanism of lesion development is unclear, and even though most patients in our study experienced spontaneous recovery, we observed the persistence of a certain degree of injury manifested by alterations in olfactory recognition and identification. Accordingly, we must be aware of possible permanent sequelae in olfactory function, as consequences of COVID-19.
The OLFAMEX survey is the first to investigate the prevalence of olfactory disorders in a Mexican, as well as Latin American, population. The study's significant strengths include the large size of the sample population, the face-toface collection of data by trained personnel, and the ability to identify persons with acute respiratory infections. Its limitations or weaknesses were the lack of control over the selfdescribed level of education, which tended to be higher than known characteristics in Mexico, as well as not distinguishing participants with a neurodegenerative disease from those that had only a direct family history, preventing a separate evaluation of those two groups. Nevertheless, our results about the olfactory condition are very revealing in our Mexican population and the association with olfactory loss paves the way for further investigations in that direction. Given the relevant prevalence of diabetes mellitus in Mexico [63], as well as in many other developed countries worldwide, there is an important unmet need to deeply investigate the impact of DM2 and obesity on the sense of smell, and in consequence, their potential roles in early mortality.

\section{Conclusions}

In agreement with previously reported epidemiologic studies, the OLFAMEX survey of a general Mexican population indicated an age-related deterioration in odor detection, recognition memory, and identification, as well as better forcedchoice identification in females. Pregnancy was associated with better odor recognition and identification. Low educational level, active smoking, and DM2 were associated with olfactory disorders. Although we are still a long way from establishing the role of olfaction and its impact on health, current efforts to standardize protocols and methodology for diagnosis and treatment [34], including cases of post-viral and COVID-19-induced loss of smell, will help increase the quality of continuing research.

Finally, these findings are also of scientific interest regarding the differential diagnosis, given that the loss of the sense of smell during the COVID-19 outbreak could already have been present at the time of the SARS-CoV-2 infection, and been caused by different etiologies or associated factors.

Acknowledgments To Alan Iván Chávez Mayoral, Mary Ann Valenzuela Morales, Silvia Georgina Mosqueda Lara, and Daniela Ramírez de León for their collaboration in carrying out the study. To Dr. Xavier Valero for his collaboration on the manufacture of the OLFAMEX-4 smell test set.

\section{Compliance with Ethics Guidelines}

Conflict of Interest The authors declare that they have no conflicts of interest. 
Human and Animal Rights and Informed Consent This article does not contain any studies with human or animal subjects performed by any of the authors.

\section{References}

Papers of particular interest, published recently, have been highlighted as:

- Of importance

-• Of major importance

1.• Mullol J, Alobid I, Mariño-Sánchez F, Izquierdo-Dominguez A, et al. The loss of smell and taste in the COVID-19 outbreak: a tale of many countries. Curr Allergy Asthma Rep. 2020;20(10):61. https://doi.org/10.1007/s11882-020-00961-1 On March 2020, scientific societies from many countries reported sudden and severe olfactory loss commonly as an isolated symptom in COVID-19, with a wide variation on the incidence reported.

2. Pang KW, Chee J, Subramaniam S, Ng CL. Frequency and clinical utility of olfactory disfunction in COVID-19? A systematic review and meta-analysis. Curr Allergy Asthma Rep. 2020;20(12):76. https://doi.org/10.1007/s11882-020-00972-y

3. Heidari F, Karim E, Firouzifar M, Khamushian P, et al. Anosmia as a prominent symptom of COVID-19 infection. Rhinology. 2020;58(3):302-3.

4. Pinto JM, Wroblewski KE, Kern DW, et al. Olfactory dysfunction predicts 5-year mortality in older adults. Hummel T, editor. PLoS One. 2014;9(10):e107541. https://doi.org/10.1371/journal.pone. 0107541.

5. Ekström I, Sjölund S, Nordin S, et al. Smell loss predicts mortality risk regardless of dementia conversion. J Am Geriatr Soc. 2017;65(6):1238-43 This study showed that mortality can be predicted from a subjective olfactory impairment, with participants with impairment being $30 \%$ more likely to die.

6. Devanand DP, Lee S, Manly J, Andrews H, Schupf N, Masurkar A, et al. Olfactory identification deficits and increased mortality in the community. Ann Neurol. 2015;78(3):401-11.

7. Pinto JM. Olfaction. Proc Am Thorac Soc. 2011;8(1):46-52.

8. Obando A, Alobid I, Gastón F, Berenguer J, Marin C, Mullol J. Should postviral anosmia be further investigated? Allergy Eur J Allergy Clin Immunol. 2009;64(10):1556-7.

9. Jaume F, Quintó L, Alobid I, Mullol J. Overuse of diagnostic tools and medications in acute rhinosinusitis in Spain: a population-based study (the PROSINUS study). BMJ Open. 2018;8(1):e018788.

10. Marin C, Laxe S, Langdon C, Berenguer J, Lehrer E, MariñoSánchez $\mathrm{F}$, et al. Olfactory function in an excitotoxic model for secondary neuronal degeneration: role of dopaminergic interneurons. Neuroscience. 2017;364:28-44.

11. Kern RC, Quinn B, Rosseau G, Farbman AI. Post-traumatic olfactory dysfunction. Laryngoscope. 2000;110(12):2106-9.

12. Langdon C, Lehrer E, Berenguer J, Laxe S, Alobid I, Quintó L, et al. Olfactory training in post-traumatic smell impairment: mild improvement in threshold performances: results from a randomized controlled trial. J Neurotrauma. 2018;35(22):2641-52.

13. Doty RL, Deems D, Stellar S. Olfactory dysfunction in parkinsonism: a general deficit unrelated to neurologic signs, disease stage, or disease duration. Neurology. 1988;38(8):1237-44.

14. Noyce AJ, Bestwick JP, Silveira-Moriyama L, Hawkes CH, Knowles CH, Hardy J, et al. PREDICT-PD: identifying risk of Parkinson's disease in the community: methods and baseline results. J Neurol Neurosurg Psychiatry. 2014;85(1):31-7.
15. Marin C, Vilas D, Langdon C, Alobid I, López-Chacón M, Haehner A, et al. Olfactory dysfunction in neurodegenerative diseases. Curr Allergy Asthma Rep. 2018;18(8):42.

16. Seiden AM, Duncan HJ. The diagnosis of a conductive olfactory loss. Laryngoscope. 2001;111(1):9-14.

17. Guilemany JM, Mariño-Sánchez FS, Angrill J, Alobid I, Centellas $\mathrm{S}$, Pujols L, et al. The importance of smell in patients with bronchiectasis. Respir Med. 2011;105(1):44-9.

18. Guilemany JM, Angrill J, Alobid I, Centellas S, Prades E, Roca J, et al. United airways: the impact of chronic rhinosinusitis and nasal polyps in bronchiectasic patient's quality of life. Allergy Eur J Allergy Clin Immunol. 2009;64(10):1524-9.

19. Alobid I, Benítez P, Cardelús S, de Borja Callejas F, Lehrer-Coriat E, Pujols L, et al. Oral plus nasal corticosteroids improve smell, nasal congestion, and inflammation in sino-nasal polyposis. Laryngoscope. 2014;124(1):50-6.

20. Guilemany JM, García-Piñero A, Alobid I, Cardelús S, Centellas S, Bartra J, et al. Persistent allergic rhinitis has a moderate impact on the sense of smell, depending on both nasal congestion and inflammation. Laryngoscope. 2009;119(2):233-8.

21. Langdon C, Guilemany JM, Valls M, Alobid I, Bartra J, Dávila I, et al. Allergic rhinitis causes loss of smell in children: the OLFAPEDRIAL study. Pediatr Allergy Immunol. 2016;27(8): 867-70.

22. Mariño-Sanchez F, Valls-Mateus M, Haag O, Alobid I, Bousquet J, Mullol J. Smell loss is associated with severe and uncontrolled disease in children and adolescents with persistent allergic rhinitis. J Allergy Clin Immunol Pract. 2018;6(5):1752-5.

23. Landis BN, Konnerth CG, Hummel T. A study on the frequency of olfactory dysfunction. Laryngoscope. 2004;114(10):1764-9.

24. Murphy C, Schubert CR, Cruickshanks KJ, Klein BE, Klein R, Nondahl DM. Prevalence of olfactory impairment in older adults. JAMA. 2002;288(18):2307-12.

25. Wysocki CJ, Gilbert AN. National Geographic Smell Survey: effects of age are Heterogenous. Ann N Y Acad Sci. 1989;561(1):1228.

26. Lin S-H, Chu S-T, Yuan B-C, Shu CH. Survey of the frequency of olfactory dysfunction in Taiwan. J Chin Med Assoc. 2009;72(2): $68-71$.

27. Brämerson A, Johansson L, Ek L, et al. Prevalence of olfactory dysfunction: the skövde population-based study. Laryngoscope. 2004;114(4):733-7.

28.• Liu G, Zong G, Doty RL, et al. Prevalence and risk factors of taste and smell impairment in a nationwide representative sample of the US population: A cross-sectional study. BMJ Open. 2016;6(11):8 11 The study demonstrated associations of age, gender, ethnicity, educational attainment, family income, alcohol consumption, and history of asthma, cancer or cardiovascular disease with chemosensory disorders on a nationwide scale.

29. Mullol J, Alobid I, Mariño-Sánchez F, Quintó L, de Haro J, BernalSprekelsen M, et al. Furthering the understanding of olfaction, the prevalence of loss of smell and risk factors: a population-based survey (OLFACAT study). BMJ Open. 2012;2(6):e001256.

30. WHO Expert Committee on Physical Status: the Use and Interpretation of Anthropometry (1993 : Geneva, Switzerland) \& World Health Organization. Physical status : the use of and interpretation of anthropometry, report of a WHO expert committee. World Health Organization; 1995. https://apps.who.int/iris/ handle/10665/37003.

31. Partida Bush, Virgilio. Proyecciones de la población de México, de las entidades federativas, de los municipios y de las localidades 2005-2050, Documento metodológico, Consejo Nacional de Población, México. 2008.

32. Larsson M, Finkel D, Pedersen NL. Odor identification: influences of age, gender, cognition, and personality. J Gerontol Ser B Psychol Sci Soc Sci. 2000;55(5):P304-10. 
33. Hummel T, Whitcroft K, Andrews $\mathrm{P}$, et al. Position paper on olfactory dysfunction. Rhinology. 2017;54(Suppl 26):1-30.

34. Pinto JM, Wroblewski KE, Kern DW, Schumm LP, McClintock MK. The rate of age-related olfactory decline among the general population of older U.S. adults. J Gerontol A Biol Sci Med Sci. 2015;70(11):1435-41.

35. Kovács T. Mechanisms of olfactory dysfunction in aging and neurodegenerative disorders. Ageing Res Rev. 2004;3(2):215-32.

36. Verbeurgt C, Wilkin F, Tarabichi M, Gregoire F, Dumont JE, Chatelain P. Profiling of olfactory receptor gene expression in whole human olfactory mucosa. PLoS One. 2014;9(5):21-6. https://doi.org/10.1371/journal.pone.0096333.

37. Schubert CR, Cruickshanks KJ, Fischer ME, Huang GH, Klein BEK, Klein R, et al. Olfactory impairment in an adult population: the beaver dam offspring study. Chem Senses. 2012;37(4):325-34.

38. Vennemann MM, Hummel T, Berger K. The association between smoking and smell and taste impairment in the general population. $\mathrm{J}$ Neurol. 2008;255(8):1121-6.

39. Gouveri E, Katotomichelakis M, Gouveris H, Danielides V, Maltezos E, Papanas N. Olfactory dysfunction in type 2 diabetes mellitus: an additional manifestation of microvascular disease? Angiology. 2014;65(10):869-76.

40. Schab F. Odor memory: taking stock. Psychol Bull. 1991;109(2): $242-51$.

41. Ochsenbein-Kölble N, von Mering R, Zimmermann R, Hummel T. Changes in olfactory function in pregnancy and postpartum. Int $\mathrm{J}$ Gynecol Obstet. 2007;97(1):10-4.

42. Gilbert A, Wysocki C. Quantitative Assessment of Olfactory Experience during Pregnancy Reports such as the two quoted above are familiar to medical personnel caring for pregnant women. A change in odor perception during pregnancy is a seemingly frequent event. As described. Psychosom Med. 1991;53:693-700.

43. Swallow B, Lindow S, Masson E, et al. Women with nausea and vomiting in pregnancy demonstrate worse health and are adversely affected by odours. J Obstet Gynaecol. 2005;25(6):544-9.

44. Laska M, Koch B, Heid B. Failure to demonstrate systematic changes in olfactory perception in the course of pregnancy. Chem Senses. 1996;21(5):567-71.

45. Cameron E. Measures of human olfactory perception during pregnancy. Chem Senses. 2007;32(8):775-82.

46. Barrera-Cruz A, Rodríguez-González A, Molina-Ayala MA. The current state of obesity in Mexico. Rev Med Inst Mex Seguro Soc. 2013;51(3):292-9.

47. Thiebaud N, Johnson MC, Butler JL, Bell GA, Ferguson KL, Fadool AR, et al. Hyperlipidemic diet causes loss of olfactory sensory neurons, reduces olfactory discrimination, and disrupts odorreversal learning. J Neurosci. 2014;34(20):6970-84.

48. Fernández-Aranda F, Agüera Z, Fernández-García J, et al. Smelltaste dysfunctions in extreme weight/eating conditions: analysis of hormonal and psychological interactions. Endocrine. 2016;51(2): 256-67.
49.• Gopinath B, Russel J, Sue CM, Flood VM, Burlutsky G, Mitchell P. Olfactory impairment in older adults is associated with poorer diet quality over 5-years. Eur J Nutr. 2016;55(3):1081-7 The epidemiological data proposed to reinforces the importance of olfaction in following dietary guidelines and in the nutritional intake of older adults, particularly women.

50. Weinstock R, Wright $\mathrm{H}$, Smith D. Olfactory dysfunction in diabetes mellitus. Physiol Behav. 1993;53(1):17-21.

51. Naka A, Riedl M, Luger A, Hummel T, Mueller CA. Clinical significance of smell and taste disorders in patients with diabetes mellitus. Eur Arch Otorhinolaryngol. 2010;267:547-50.

52. Gascón C, Santaolalla F, Martínez A, Sánchez del Rey A. Usefulness of the BAST-24 smell and taste test in the study of diabetic patients: a new approach to the determination of renal function. Acta Otolaryngol. 2013;133(4):400-4.

53. Finkel D, Pedersen N, Larsson M. Olfactory functioning and cognitive abilities: a twin study. J Gerontol B Psychol Sci Soc Sci. 2001;56(4):P226-33.

54. Upadhyay U, Holbrook E. Olfactory loss as a result of toxic exposure. Otolaryngol Clin N Am. 2004;37(6):1185-207.

55. Deems D, Doty R, Settle G, et al. Smell and taste disorders, a study of 750 patients from the University-of-Pennsylvania smell and taste center. Arch Otolaryngol Neck Surg. 1991;117(5):519-28.

56. Wilson R, Arnold S, Schneider J, et al. Olfactory impairment in presymptomatic Alzheimer's disease. Ann N Y Acad Sci. 2009;1170:730-5.

57. Berendse H, Booij J, Francot C. B et al. subclinical dopaminergic dysfunction in asymptomatic Parkinson's disease patients' relatives with a decreased sense of smell. Ann Neurol. 2001;50(1):34-41.

58. Vilas D, Tolosa E, Quintana M, Pont-Sunyer C, Santos M, Casellas A, et al. Olfaction in LRRK2 linked Parkinson's disease: is it different from idiopathic Parkinson's disease? J Parkinsons Dis. 2020;10(3):951-8.

59. Jennings D, Siderowf A, Stern M, Seibyl J, Eberly S, Oakes D, et al. Conversion to Parkinson disease in the PARS hyposmic and dopamine transporter-deficit prodromal cohort. JAMA Neurol. 2017;74(8):933-40

60. Wrobel B, Leopold D. Clinical assessment of patients with smell and taste disorders. Otolaryngol Clin N Am. 2004;37:1127-42.

61. de Kruijk J, Leffers P, Menheere P, et al. Olfactory function after mild traumatic brain injury. Brain Inj. 2003;17:73-8.

62. Izquierdo-Dominguez A, Rojas-Lechuga MJ, Mullol J, Alobid I. Olfactory Dysfunction in the COVID-19 Outbreak. J Investig Allergol Clin Immunol. 2020;30(5):317-326. https://doi.org/10. 18176/jiaci.0567.

63. Hernández-Ávila M, Gutiérrez J, Reynoso-Noverón D. Diabetes mellitus in Mexico. Status of the epidemic. Salud Publica Méx. 2013;55(Suppl 2):S129-36.

Publisher's Note Springer Nature remains neutral with regard to jurisdictional claims in published maps and institutional affiliations. 